\title{
Lack of effect of TCAP on conditioned avoidance learning in rats'
}

LEON S. OTIS AND GORDON T. PRYOR, BIOBEHAVIORAL SCIENCES DEPARTMENT, STANFORD RESEARCH INSTITUTE, Menlo Park, Calif. 94025

TCAP has been reported to enhance the retention of a discriminated lever-pressing avoidance response in rats, presumably by increasing the rate of RNA synthesis during the learning trials. In three experiments using a pole-climb avoidance response and multiple injections, we were unable to demonstrate enhancement. In two additional experiments designed to confirm the original report, results were also negative.

Chamberlain, Rothchild, \& Gerard (1963) reported that a single injection of 1, 1, 3-tricyano, 2-amino, 1-propene (TCAP), a dimer of malononitrile, enhanced the retention of a discriminated lever-pressing avoidance response in rats. The hypothesized mechanism of enhancement was an increased rate of RNA synthesis during the learning trials (Egyhazi \& Hyden, 1961). However, Brush, Davenport, \& Polidora (1966) were unable to demonstrate that TCAP enhanced acquisition or retention of a shuttle-box avoidance response or a 6-unit water maze habit in rats, whether the animals were given one, four, or nine injections, or were maintained for 80 days on a diet containing TCAP. On the other hand, Essman (1966) reported that three daily injections of TCAP in adult mice diminished the amnesic effects of a single electroconvulsive shock following one-trial learning of a passive avoidance response. He interpreted his results as indicating that the TCAP shortened consolidation time.

In view of the conflicting results cited above and the results of a number of unpublished studies known to the authors, we felt it important to report our experience with TCAP. In a series of three experiments we failed to observe any enhancement of acquisition of a pole-climb avoidance response by TCAP. Also, in two additional experiments patterned after the original experiment reported by Chamberlain et al (1963), we failed to replicate their results.

Pole-Climb Avoidance Studies. Male Long-Evans rats weighing approximately $300 \mathrm{~g}$ were injected ip. $(1 \mathrm{ml} / \mathrm{kg})$ with drug or placebo daily for four days prior to training and throughout the training phase $(4 \mathrm{~h}$ before each training session). TCAP was dissolved in a solution of $70 \% \mathrm{ETOH}$ and $30 \%$ $\mathrm{NaCl}(0.9 \%)$, which was also used as the placebo.

In Experiment 1, four groups of 12 animals each were treated with placebo or 5,10 , or $20 \mathrm{mg} / \mathrm{kg}$ TCAP. In Experiment 2, two groups of 12 animals each were treated with placebo or $20 \mathrm{mg} / \mathrm{kg}$ TCAP. Experiment 3 was a replication of Experiment 2.

The conditioning unit was an 11 in. $x 12$ in. $\times 13^{1 / 2}$ in. chamber with a grill floor and a pole suspended from the center of the ceiling. Jumping onto the pole terminated a trial. Twelve such units, each housed in its own sound-deadened chamber, allowed simultaneous testing of 12 animals equally divided among the various conditions. Each of five daily training sessions consisted of 20 trials. The CS was a 2-cps flashing light and buzzer that preceded by $15 \mathrm{sec}$ and overlapped the UCS, a $0.6-\mathrm{mA}$ shock to the feet for $45 \mathrm{sec}$ if the animal failed to respond. The intertrial interval varied randomly from 1 to $4 \mathrm{~min}$.

Lever-Press vs Pole-Climb Avoidance Studies. Forty-eight male Long-Evans rats weighing 200 to $250 \mathrm{~g}$ were used in each of two replicated experiments (No. 4 and 5) designed to repeat as closely as possible the Chamberlain et al (1963) experiment and to compare acquisition of the lever-press and the pole-climb responses under TCAP. The animals were formed into two groups: one trained using the pole, and the other trained using the lever. Half of each group served as controls and were injected with placebo; the other half were injected with $15 \mathrm{mg} / \mathrm{kg}$ TCAP.

The apparatus was the same as in Experiments 1-3 except that a lever, mounted $4 \mathrm{in}$. above the floor in the center of one end, replaced the pole for half of the animals. Following the procedure of Chamberlain et al (1963), on Day 1 the animals were given 25 pretraining trials consisting of 25 randomly spaced 10-sec shocks $(1.0 \mathrm{~mA})$ in the apparatus with the response manipulandum removed. On Days 2, 3, and 4 they were given 25 training trials per day with the pole or lever in place. An ambient light was on in each chamber. The CS was a 2000-cps tone which preceded (by $10 \mathrm{sec}$ ) and overlapped the UCS (a 1.0-mA shock to the feet). If the animal failed to respond, the CS and UCS remained on for a maximum of 90 sec. A single injection of placebo or TCAP $(1 \mathrm{ml} / \mathrm{kg})$ was given ip. $45 \mathrm{~min}$ before the first training session on Day 2.

Results. The results of Experiments 1-3 are summarized in Fig. 1 in terms of mean number of avoidance responses (CARs) and mean latency to climb the pole per block of 20 trials. A repeated-measures analysis of variance over blocks of trials was done for each measure for each experiment. In none of the experiments did the number of CARs significantly differentiate the groups. In Experiment 3 the drug by block interaction was significant $(p \leqslant .05)$ for the latency data. The slightly better performance of the TCAP group during the first two blocks accounts for this significant interaction and reflects faster escape; thereafter their performance was almost identical to that of the controls.

The results of Experiments 4 and 5 are summarized in Fig. 2 in terms of mean number of CARs and mean latency to respond per block of 25 trials. Analysis of the data failed to reveal any differences due to TCAP for either measure. Although both groups readily learned to escape the shock, only the group using the pole learned to avoid the shock. A large difference between groups using the lever and those using the pole was evident on both measures $(\mathrm{p} \leqslant .001)$.

Discussion. This series of five experiments failed to provide evidence for an enhancing effect of TCAP in avoidance learning or retention under our conditions of drug administration and testing.

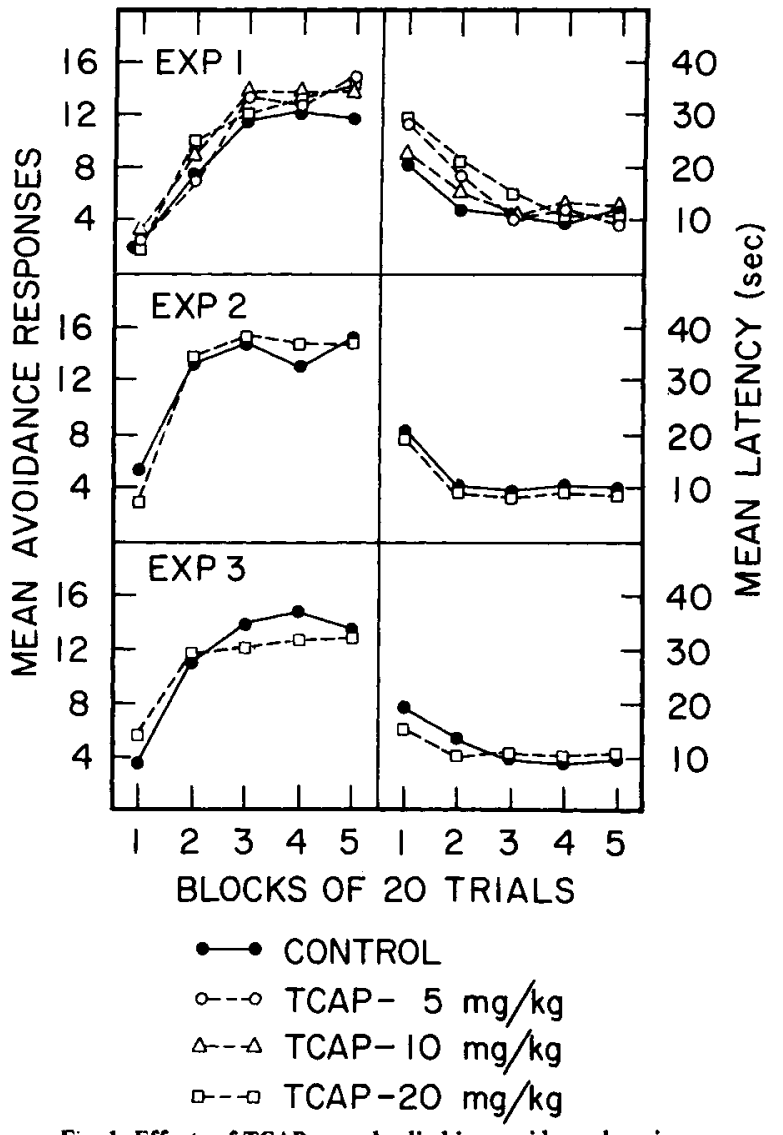

Fig. 1. Effects of TCAP on pole-climbing avoidance learning. 

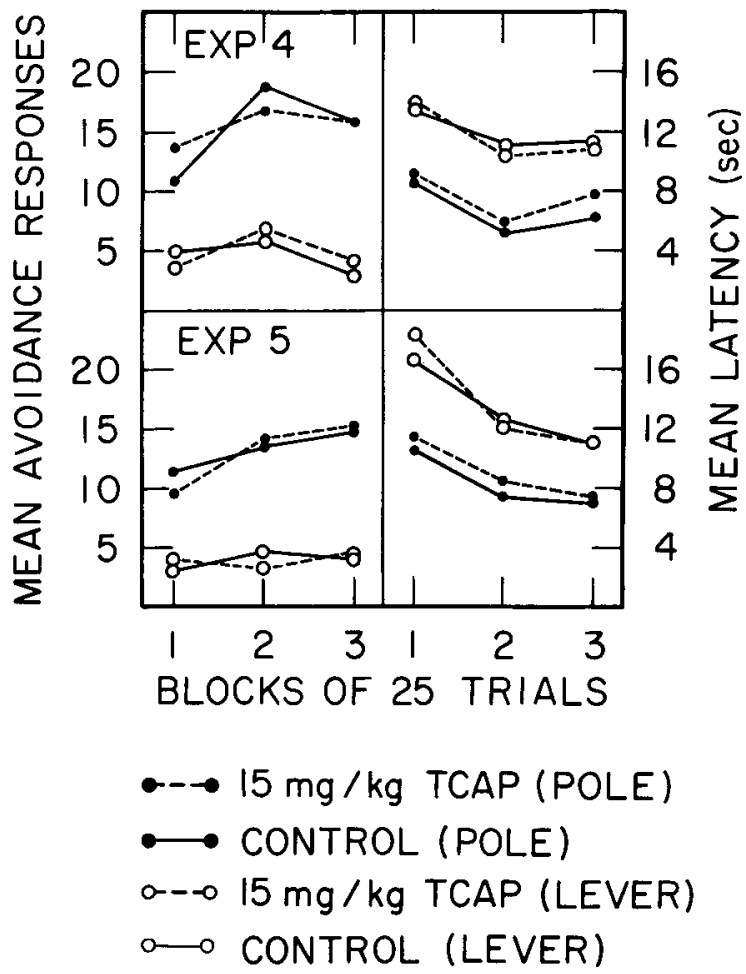

Fig. 2. Comparison of effects of TCAP on pole and lever avoidance learning.

Concerning our attempts to repeat the experiments of Chamberlain et al (1963), it is always difficult, if not impossible, to carry out an exact replication of another laboratory's procedures. Our attempt was no exception. Our conditioning apparatus was different in several respects from theirs (e.g., cylindrical vs rectangular). We used a pigmented strain of rats; they used an albino strain. Finally, we used a 2000-cps tone as the CS; they used a loud buzzer. Any or all of these procedural differences might account for our failure to confirm their results. On the other hand, assuming that their results are valid, the enhancing effects of a single injection of TCAP cannot be considered to be very general. Under a similar schedule of dosage injection and testing used by Chamberlain et al (1963), we found that TCAP was without effect on the acquisition of retention of a pole-climb avoidance response that our animals learned at about the same rate as their animals learned a lever-press response. Brush et al (1966) also failed to find enhancement of a shuttle-box avoidance response following a single injection of TCAP, thus further restricting the generality of the results of the Chamberlain et al (1963) experiment.

Concerning the three experiments using multiple injections of TCAP, our results are also in essential agreement with those of Brush et al (1966), who failed to find enhancement of acquisition or reversal of a 6-unit maze habit. However, recent results suggest that the age of the animals at the time TCAP is administered may be a critical variable. Chronic administration of TCAP to rats-beginning prenatally, at birth, or at weaning-was reported to enhance Y-maze spatial discrimination and reversal performance (Schmidt \& Davenport, 1967). Additional support for this hypothesis is provided by Essman (1967), who found that chronic administration of the drug to mice from three to 16 days of age resulted in enhancement of acquisition of an escape response from a water maze when the animals were tested at 25 days of age. On the other hand, the report by Essman (1966) that TCAP antagonized the amnesic effects of ECS and increased brain RNA in adult mice suggests that enhancement of learning and/or retention might be expected even in adults. It may be that such enhancement, if present in the adult, is more difficult to demonstrate. Clearly, our experiments and those of Brush et al (1966) were unable to do so.

\section{REFERENCES}

BRUSH, F. R., DAVENPORT, J. W., \& POLIDORA, V. J. TCAP: Negative results in avoidance and water maze learning and retention. Psychon. Sci., 1966, 4, 183-184.

CHAMBERLAIN, T. J., ROTHCHILD, G. H., \& GERARD, R. W. Drugs affecting RNA and learning. Proc. Natl. Acad. Sci., U. S., 1963, 49, 918-924.

EGYHAZI, E., \& HYDEN, H. Experimentally induced changes in the base composition of the ribonucleic acids of isolated nerve cells and their oligodendroglial cells. J. Biophys. Biochem. Cytol., 1961, 10, 402410.

ESSMAN, W. B. Effect of tricyanoaminopropene on the amnesic effect of electroconvulsive shock. Psychopharmacologia, 1966, 9, 426-433.

ESSMAN, W. B. Facilitation of maze acquisition by mice with tricyanoaminapropene (TCAP) given during early postnatal development. Psychon. Sci., 1967, 9, 51-52.

SCHMIDT, M. J., \& DAVENPORT, J. W. TCAP: Facilitation of learning in hypothyroid rats. Psychon. Sci., 1967, 7, 185-186.

\section{NOTE}

1. This research was supported by Contract Nonr 2993(00) between the Office of Naval Research and Stanford Research Institute. Mrs. Judith Colwell and Mr. Val Putnam assisted in the conduct of the research. 